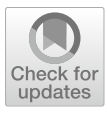

Cite as

Nano-Micro Lett.

(2021) $13: 177$

Received: 16 April 2021

Accepted: 24 June 2021

Published online: 17 August 2021

(C) The Author(s) 2021

\section{Mediating the Local Oxygen-Bridge Interactions of Oxysalt/Perovskite Interface for Defect Passivation of Perovskite Photovoltaics}

\author{
Ze Qing Lin ${ }^{1}$, Hui Jun Lian ${ }^{1}$, Bing Ge ${ }^{1}$, Ziren Zhou ${ }^{1}$, Haiyang Yuan ${ }^{1}{ }^{凶}$, Yu Hou ${ }^{1}$, \\ Shuang Yang ${ }^{1}$, Hua Gui Yang ${ }^{1}$
}

\title{
HIGHLIGHTS
}

- Oxyacid anions $\left(\mathrm{NO}_{3}{ }^{-}, \mathrm{SO}_{4}{ }^{2-}, \mathrm{CO}_{3}{ }^{2-}, \mathrm{PO}_{4}{ }^{3-}\right.$ and $\left.\mathrm{SiO}_{3}{ }^{2-}\right)$ were investigated both theoretically and experimentally about their passivation effect on $\mathrm{CsPbI}_{2} \mathrm{Br}$ perovskite interface.

- Adjustment of oxysalt layer thickness can optimize the surface band position that could be beneficial for electronic band alignment at perovskite/transport layer interface.

- Using silicate as a passivator, the $\mathrm{CsPbI}_{2} \mathrm{Br}$ solar cells achieved a PCE of $17.26 \%$ with an open-circuit voltage of $1.36 \mathrm{~V}$. This strategy is also effective for organic-inorganic perovskite solar cells.

ABSTRACT Passivation, as a classical surface treatment technique, has been widely accepted in start-of-the-art perovskite solar cells (PSCs) that can effectively modulate the electronic and chemical property of defective perovskite surface. The discovery of inorganic passivation compounds, such as oxysalts, has largely advanced the efficiency and lifetime of PSCs on account of its favorable electrical property and remarkable inherent stability, but a lack of deep understanding of how its local configuration affects the passivation effectiveness is a huge impediment for future interfacial molecular engineering. Here, we demonstrate the central-atom-dependent-passivation of oxysalt on perovskite surface, in which the central atoms of oxyacid anions dominate the interfacial oxygen-bridge strength. We revealed that the balance of local interactions between the central atoms of oxyacid

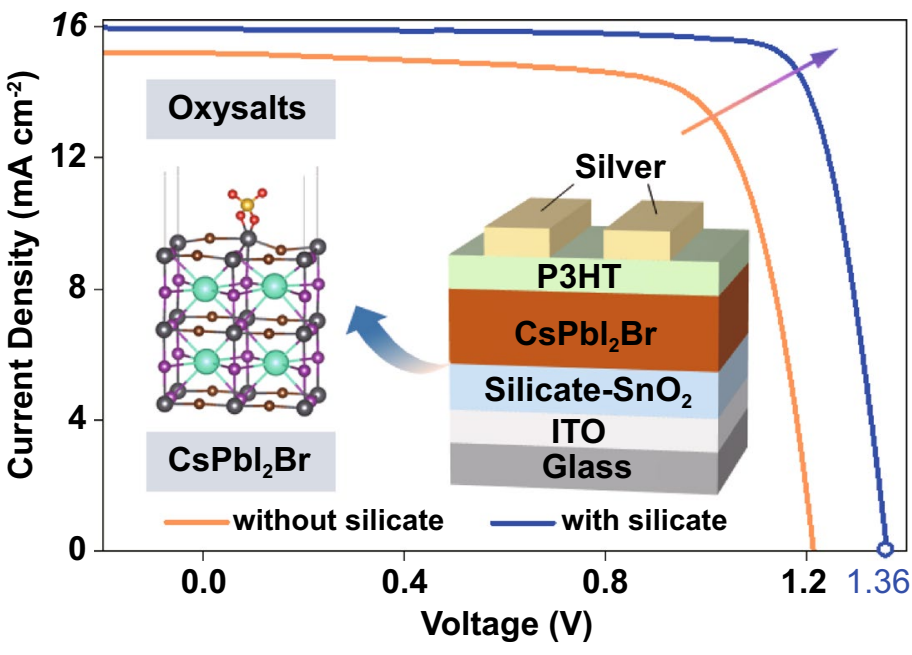
anions (e.g., N, C, S, P, Si) and the metal cations on perovskite surface (e.g., Pb) generally determines the bond formation at oxysalt/perovskite interface, which can be understood by the bond order conservation principle. Silicate with less electronegative Si central atoms provides strong $\mathrm{O}-\mathrm{Pb}$ motif and improved passivation effect, delivering a champion efficiency of $17.26 \%$ for $\mathrm{CsPb}_{2} \mathrm{Br}$ solar cells. Our strategy is also universally effective in improving the device performance of several commonly used perovskite compositions.

KEYWORDS Solar cell; Lead halide perovskite; Passivation; Oxysalt; Central atom

Ze Qing Lin and Hui Jun Lian contributed equally to this work

$\bowtie$ Haiyang Yuan, hyyuan@ecust.edu.cn; Shuang Yang, syang@ecust.edu.cn

1 Key Laboratory for Ultrafine Materials of Ministry of Education, Shanghai Engineering Research Center of Hierarchical Nanomaterials, School of Materials Science and Engineering, East China University of Science and Technology, Shanghai 200237, People's Republic of China 


\section{Introduction}

Lead halide perovskites have been discovered as a class of promising light-harvesting materials for photovoltaics due to their excellent optoelectronic properties including high optical absorption coefficient, adjustable bandgap and long carrier diffusion length [1-6]. During the past decade, the certificated power conversion efficiency of perovskite solar cells (PSCs) has surpassed 25\%, showing a competitive performance compared to crystalline silicon solar cells [7]. Typical PSCs generally adopt the thin-film configuration comprising polycrystalline perovskite films stacked between transport layers and electrodes, whose surface or interface is crucial for device performance and longevity [8-10]. However, the surfaces or grain boundaries of perovskite films that enriched with charge trapping centers and mobile species would inevitably cause non-radiative recombination and structural decomposition, which is a major limit for the commercialization of perovskite photovoltaics [11-14].

Most often the defective perovskite surface is modified by organic functional molecules, such as ammonium halides, fullerene derivatives, zwitterions and polymers, which can passivate the charge traps by chemical interactions or charge neutralization [15-23]. Meanwhile, the perovskite community also gained inorganic passivation materials that are believed to be intrinsically more stable, which have indeed advanced the performance and stability of PSCs [24-28]. For instance, decorating the perovskite surface with a potassium halide layer can immobilize the surplus halides through complexing with potassium into benign compounds, and maximized the photoluminescence quantum yields up to $95 \%$ as well as high carrier mobility over $40 \mathrm{~cm}^{2} \mathrm{~V}^{-1} \mathrm{~s}^{-1}$ [29]. Most recently, Yang et al. reported an inorganic oxysalt interface by in situ converting perovskite surface into inorganic, strongly interacted, wide bandgap oxysalt capping layers that enabled photovoltaic devices with only $3.2 \%$ efficiency loss for $1200 \mathrm{~h}$ under operational condition [1]. Above-mentioned cases feature with a semiconductor-insulator interface, and particularly, the oxysalt/ perovskite configuration is conceptually similar to the welldeveloped $\mathrm{SiO}_{2}-\mathrm{Si}$ passivation interface. Chemical bonding at the interface primarily determines the ultimate activity of defects and mobile sites [30, 31]. For inorganic passivation materials, their microscopic working mechanism, such as chemical bonding, electronic structures, has not yet been well resolved from both experimental and theoretical perspectives, which is urgently required for the development of this field.

In this work, through extensive modeling and experimental characterizations, we investigated the local chemical interaction of oxyacid anions $\left(\mathrm{NO}_{3}{ }^{-}, \mathrm{SO}_{4}{ }^{2-}, \mathrm{CO}_{3}{ }^{2-}\right.$, $\mathrm{PO}_{4}{ }^{3-}$ and $\mathrm{SiO}_{3}{ }^{2-}$ ) on perovskite surface and revealed its central-atom-dependent-passivation phenomenon in perovskite devices. We found that the electronegativity of central atoms of oxyacid anions (X) determines the bonding strength of oxygen bridge to surface undercoordinated cations of perovskite $(\mathrm{M})$ that can be interpreted by the bond order conservation principle. A less electronegative $\mathrm{X}$ atom, such as $\mathrm{Si}$, offers a stronger local $\mathrm{XO}-\mathrm{M}$ interaction and thus more reliable passivation effect. In addition, careful adjustment of oxysalt layer thickness also optimizes the surface band position that could be beneficial for electronic band alignment at perovskite/transport layer interface. These simultaneous improvements by using silicate as passivator lead to an enhanced open-circuit voltage $\left(V_{\mathrm{OC}}\right)$ from 1.22 to $1.36 \mathrm{~V}$ and a significantly increased PCE from 13.52 to $17.26 \%$ for inorganic $\mathrm{CsPb}_{2} \mathrm{Br}$ solar cells.

\section{Experimental Section}

\subsection{Computational Details}

All first-principle calculations are carried out using Vienna $\mathrm{Ab}$ initio Simulation Package (VASP), with the employment of the density functional theory (DFT) [32]. The exchange-correlation interactions are treated using Perdew-Burke-Ernzerhof (PBE) functional of a generalized gradient approximation (GGA) method [33]. The core-valence electron interaction was represented with the project-augmented wave (PAW) method [34]. On the plane wave basis, an energy cutoff of $450 \mathrm{eV}$ is employed. The Broyden method was employed for geometric optimization until the forces on each relaxed atom were less than $0.05 \mathrm{eV}^{-1}$. The more stable $\mathrm{PbIBr}$-terminated $\mathrm{CsPbI}_{2} \mathrm{Br}(001)$ surface was selected in our calculation (Fig. S1), which was molded as a four layers $p(2 \times 2)$ with a vacuum of $20 \AA$ in our calculation. A corresponding $1 \times 1 \times 1 \mathrm{k}$-point mesh was used. In the optimization, the bottom two layers were fixed, and the top two layers and the adsorbates were fully relaxed. The DFT-D3 method was used to the weak interaction [35]. 


\subsection{Chemicals}

Cesium iodide (CsI, 99.999\%), lead iodide $\left(\mathrm{PbI}_{2}, 99.9 \%\right)$, lead bromide $\left(\mathrm{PbBr}_{2}, 99.9 \%\right)$, dimethyl sulfoxide (DMSO, 99.8\%), isopropanol (IPA, $\geq 99.5 \%$ ), bis(trifluoromethane) sulfonimide lithium salt (Li-TFSI, 99.95\%), 4-tert-Butylpyridine (tBP, 96\%) and toluene (TL, anhydrous, 99.8\%) were purchased from Sigma-Aldrich. Tin (IV) oxide (15\% in $\mathrm{H}_{2} \mathrm{O}$ colloidal dispersion) was purchased from AlfaAesar. Nickel(II) chloride hexahydrate $\left(\mathrm{NiCl}_{2} \cdot 6 \mathrm{H}_{2} \mathrm{O}\right.$, $\mathrm{AR}, \geq 98.0 \%)$, citric acid monohydrate $\left(\mathrm{C}_{6} \mathrm{H}_{8} \mathrm{O}_{7} \cdot \mathrm{H}_{2} \mathrm{O}\right.$, $\mathrm{AR}, \geq 99.5 \%)$, sodium sulfate $\left(\mathrm{Na}_{2} \mathrm{SO}_{4}, \mathrm{AR}, \geq 99.0 \%\right)$, sodium carbonate $\left(\mathrm{Na}_{2} \mathrm{CO}_{3}, \mathrm{AR}, \geq 99.8 \%\right)$, sodium nitrate $\left(\mathrm{NaNO}_{3}, \mathrm{AR}, \geq 99.0 \%\right)$, trisodium phosphate dodecahydrate $\left(\mathrm{Na}_{3} \mathrm{PO}_{4} \cdot 12 \mathrm{H}_{2} \mathrm{O}, \mathrm{AR}, \geq 98.0 \%\right)$, sodium metasilicate nonahydrate $\left(\mathrm{Na}_{2} \mathrm{SiO}_{3} \cdot 9 \mathrm{H}_{2} \mathrm{O}, \mathrm{AR}, \geq 98.0 \%\right)$ were purchased from Sinopharm Chemical Reagent Co., Ltd. Formamidinium iodide (FAI) was purchased from Great Cell. Methylammonium iodide (MAI), methylammonium chloride (MACl), poly(3-hexylthiophene-2,5-diyl) (P3HT) were obtained from Xi' an Polymer Light Technology Corp. 2,2', 7,7'-tetrakis-( $N, N$-di-4-methoxyphenylamino)-9,9'-spirobifluorene] (spiro-OMeTAD), [6, 6]-phenyl- $\mathrm{C}_{61}$-butyric acid methyl ester $\left(\mathrm{PC}_{61} \mathrm{BM}, 99.5 \%\right)$ and bathocuproine (BCP, 99\%) were purchased from Nichem chemicals. Fluorine-doped tin oxide (FTO) substrates $\left(8 \Omega \mathrm{sq}^{-1}\right)$ and indium-doped tin oxide (ITO) substrates ( $7 \Omega \mathrm{sq}^{-1}$ ) were purchased from Nippon Sheet Glass.

\subsection{Preparation of Solutions and Devices}

\subsubsection{Preparation of Precursor Solutions}

$1 \mathrm{~mL}$ of $\mathrm{SnO}_{2}$ colloidal solution ( $15 \mathrm{wt} \%$ ) was firstly diluted in $5 \mathrm{~mL}$ of deionized water. Then, sodium salts with different anions were introduced into the diluted $\mathrm{SnO}_{2}$ solution with stirring at room temperature overnight. The concentration of sodium salts in $\mathrm{SnO}_{2}$ solution was $0.05 \mathrm{M}$. $\mathrm{CsPbI}_{2} \mathrm{Br}$ precursor solution was prepared by dissolving $311.77 \mathrm{mg}$

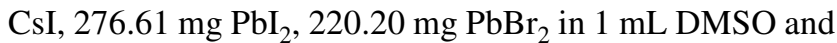
stirring at $50{ }^{\circ} \mathrm{C}$ overnight. The $\mathrm{CsPbI}_{2} \mathrm{Br}$ precursor was filtered by a $0.2 \mu \mathrm{m}$ polytetrafluoroethylene filter before use. P3HT solution was prepared by dissolving $15 \mathrm{mg}$ P3HT in $1 \mathrm{~mL}$ toluene and stirring at $70{ }^{\circ} \mathrm{C}$ for $1 \mathrm{~h}$. For FA-based devices, $622.35 \mathrm{mg} \mathrm{PbI}_{2}$ was dissolved in $900 \mu \mathrm{L}$ DMF and
$100 \mu \mathrm{L}$ DMSO and stirred at $60{ }^{\circ} \mathrm{C}$ overnight before use. $94.58 \mathrm{mg} \mathrm{FAI}$ and $7.42 \mathrm{mg} \mathrm{MACl}$ were dissolved in $1 \mathrm{~mL}$ IPA to obtain the FAI/MACl precursor. The spiro-OMeTAD solution was prepared by mixing $80 \mathrm{mg}$ spiro-OMeTAD, 54 $\mu \mathrm{L}$ Li-TFSI solution (260 mg Li-TFSI in $1 \mathrm{~mL}$ acetonitrile) and $11.2 \mu \mathrm{L} 4$-tBP in $1 \mathrm{~mL}$ chlorobenzene. For MA-based cells, $599.31 \mathrm{mg} \mathrm{PbI}_{2}$ was dissolved in $700 \mu \mathrm{L} \mathrm{DMF}$ and $300 \mu \mathrm{L}$ DMSO and stirred at $60{ }^{\circ} \mathrm{C}$ overnight. $40 \mathrm{mg}$ MAI was dissolved in $1 \mathrm{~mL}$ isopropanol to obtain MAI precursor.

\subsubsection{Device Fabrication}

We adopted a planar heterojunction structure (ITO/SnO ${ }_{2} /$ perovskite/P3HT/Ag) in our work. Firstly, the patterned ITO substrates were washed by ultrasonication with soap, deionized water, acetone and isopropanol, respectively, for $30 \mathrm{~min}$, then dried by nitrogen flow and finally treated with ultraviolet ozone cleaner for $30 \mathrm{~min}$. $\mathrm{SnO}_{2}$ solutions were spin-coated onto the glass/ITO substrates at $3000 \mathrm{rpm}$ for $30 \mathrm{~s}$ in ambient air, followed by annealing at $150{ }^{\circ} \mathrm{C}$ in muffle furnace with the heating rate of $2{ }^{\circ} \mathrm{C} \mathrm{min}{ }^{-1}$ for $30 \mathrm{~min}$. After cooling to room temperature, the substrates were treated with ultraviolet ozone for $15 \mathrm{~min}$ and then transferred to the nitrogen-filled glovebox. Subsequently, $40 \mu \mathrm{L} \mathrm{CsPbI}_{2} \mathrm{Br}$ precursor was loaded onto the substrate and spin-coated via a two-step process with $1000 \mathrm{rpm}$ for $10 \mathrm{~s}$ and $4000 \mathrm{rpm}$ for $20 \mathrm{~s}$. The $\mathrm{CsPbI}_{2} \mathrm{Br}$ layer was obtained by annealing the precursor film at $42{ }^{\circ} \mathrm{C}$ for $2 \mathrm{~min}$ and $160{ }^{\circ} \mathrm{C}$ for $10 \mathrm{~min}$. P3HT transport layer was deposited onto the $\mathrm{CsPbI}_{2} \mathrm{Br}$ film by spin coating $20 \mu \mathrm{L}$ P3HT solution at $4000 \mathrm{rpm}$ for $30 \mathrm{~s}$ and followed by annealing at $120{ }^{\circ} \mathrm{C}$ on a hotplate. For the FAbased perovskite fabrication, two-step sequential deposition method was employed by spin coating $15 \mu \mathrm{L} \mathrm{PbI}_{2}$ precursor at $2000 \mathrm{rpm}$ for $30 \mathrm{~s}$, and then spin coating $35 \mu \mathrm{L} \mathrm{FAI} /$ $\mathrm{MACl}$ precursor on the top of the $\mathrm{PbI}_{2}$ film at $3500 \mathrm{rpm}$ for $30 \mathrm{~s}$, followed by annealing at $150{ }^{\circ} \mathrm{C}$ for $15 \mathrm{~min}$. Next, 15 $\mu \mathrm{L}$ spiro-OMeTAD solution was deposited onto the $\mathrm{FAPbI}_{3}$ film by spin coating at $4000 \mathrm{rpm}$ for $30 \mathrm{~s}$. For the MA-based perovskite fabrication, $15 \mu \mathrm{L} \mathrm{NiO}_{x}$ precursor $(50.79 \mathrm{mg}$ $\mathrm{NiCl}_{2} \cdot 6 \mathrm{H}_{2} \mathrm{O}$ and $60 \mathrm{mg}$ citric acid monohydrate in $1 \mathrm{~mL}$ DMF) was deposited on the FTO substrates in ambient air at $4000 \mathrm{rpm}$ for $60 \mathrm{~s}$ and then annealed at $100^{\circ} \mathrm{C}$ for $10 \mathrm{~min}$ on a hotplate and $400{ }^{\circ} \mathrm{C}$ for $1 \mathrm{~h}$ in muffle furnace with the heating rate of $2{ }^{\circ} \mathrm{C} \mathrm{min}^{-1}$ to obtain the $\mathrm{NiO}_{\mathrm{x}}$ HTL. $15 \mu \mathrm{L}$ $\mathrm{Na}_{2} \mathrm{SiO}_{3}$ solution $\left(5 \mathrm{mg} \mathrm{mL}^{-1}\right.$ in water) was spin-coated onto 
the $\mathrm{NiO}_{\mathrm{x}}$ layer and annealed at $150{ }^{\circ} \mathrm{C}$ for $30 \mathrm{~min}$ in muffle furnace. Then, two-step sequential deposition method was employed to fabricate perovskite films by spin coating 15 $\mu \mathrm{L} \mathrm{PbI}_{2}$ precursor and $35 \mu \mathrm{L}$ MAI precursor in sequence at $3000 \mathrm{rpm}$ for $30 \mathrm{~s}$ and $5000 \mathrm{rpm}$ for $30 \mathrm{~s}$, followed by annealing at $115{ }^{\circ} \mathrm{C}$ on a hotplate for $10 \mathrm{~min}$. Next, $15 \mu \mathrm{L}$ $\mathrm{PC}_{61} \mathrm{BM}\left(20 \mathrm{mg} \mathrm{mL}^{-1}\right.$ in chlorobenzene) and $35 \mu \mathrm{L} \mathrm{BCP}$ $\left(0.5 \mathrm{mg} \mathrm{mL}^{-1}\right.$ in ethanol) were spin-coated on the top of the $\mathrm{MAPbI}_{3}$ films at $2000 \mathrm{rpm}$ for $45 \mathrm{~s}$, and $4000 \mathrm{rpm}$ for $45 \mathrm{~s}$, respectively. $\mathrm{Ag}$ or $\mathrm{Au}$ was finally thermally evaporated as a back electrode.

\subsection{Characterization}

Fourier-transform infrared (FTIR) spectroscopy was measured by FTIR Nicolet 6700. Raman spectroscopy (Raman) was performed by Laser Raman InVia Reflex. The surface morphology and cross section morphology were collected by field emission scanning electron microscopy (FESEM, HITACHI S4800). X-ray diffraction (XRD) patterns were recorded with an X-ray diffractometer Bruker D8 Advance operated $\mathrm{Cu} \mathrm{K} \alpha$ radiation. UV-vis spectra were collected using a Cary 500 UC-Vis-NIR spectrophotometer. Photoluminescence (PL) spectra were acquired at room temperature by exciting the samples deposited onto a non-conducting glass with the Fluorolog-3-p spectrophotometer under an excitation wavelength of $380 \mathrm{~nm}$. Time-resolved PL experiments were performed by exciting the samples deposited onto glass substrates using the Endinburgh FLS890 spectrometer under ambient conditions. X-ray photoelectron spectroscopy (XPS, PHI5300, Mg anode, $250 \mathrm{~W}, 14 \mathrm{kV}$ ) was used to analyze the chemical states of the ETL layers, and the binding energy of the $\mathrm{C} 1 \mathrm{~s}$ peak at $284.8 \mathrm{eV}$ was taken as an internal reference. Ultraviolet photoelectron spectroscopy (UPS) was recorded with He source of incident energy of $21.22 \mathrm{eV}$ (He 1 line) in Ningbo Institute of Industrial Technology, CAS, Ningbo. The current density-voltage (J-V) curves of the photovoltaic devices were measured using a Keithley 2400 digital sourcemeter with a scan rate of $0.15 \mathrm{~V} \mathrm{~s}^{-1}$ under simulated AM 1.5G irradiation (Solar IV-150A, Zolix). Before each measurement, light intensity was calibrated with a standard Newport calibrated KG5-filtered Si reference cell. The external quantum efficiency (EQE) spectra were measured by a Zolix-SCS600 system, calibrated by Si reference solar cell. The electrochemical impedance spectra (EIS) were measured out using an electrochemical workstation (Parstat 2273, Princeton) in the frequency range of $1 \mathrm{MHz}$ and $1 \mathrm{~Hz}$ under different positive bias voltages at dark conditions. The steady-state photocurrent output of the solar cell devices was measured by biasing the device at maxing power point by a Keithley 2400 digital sourcemeter. Devices were masked with a metal aperture to define the active area of $0.0625 \mathrm{~cm}^{2}$. To obtain the transient photovoltage (TPV) measurements, we exposed our perovskite solar cells to 0.1 sun background illumination and recorded the transit signal under attenuated laser pulse by an oscilloscope (InfiniiVision $3000 \mathrm{~T} \mathrm{X}$ ). The wavelength of the laser was $532 \mathrm{~nm}$, and the pulse width was $<10 \mathrm{~ns}$.

\section{Results and Discussion}

\subsection{Theoretical Analysis of Interactions between Oxyacid Anions and $\mathrm{CsPbI}_{2} \mathrm{Br}$}

To quantitatively evaluate the interactions of different oxyacid anions $\left(\mathrm{NO}_{3}{ }^{-}, \mathrm{CO}_{3}{ }^{2-}, \mathrm{SiO}_{3}{ }^{2-}, \mathrm{PO}_{4}{ }^{3-}, \mathrm{SO}_{4}{ }^{2-}\right)$ on perovskite, we first optimized the atomic structures of these oxyacid anions on $\mathrm{CsPbI}_{2} \mathrm{Br}$ perovskite (001) surface (Fig. S2), whose inorganic composition would be beneficial for experimentally isolating the surface interactions of oxysalts by spectroscopy studies. We found that the bidentate interaction structures of oxyacid anions on $\mathrm{CsPb}_{2} \mathrm{Br}(001)$ are more stable, in which two bridge $\mathrm{O}$ atoms in an oxyacid anion bind with one $\mathrm{Pb}$ site (Fig. 1a). Then, we introduced the crystal orbital Hamilton population (COHP) between the $\mathrm{Pb}$ site and $\mathrm{O}$ atom on $\mathrm{CsPbI}_{2} \mathrm{Br}$ (001) with different oxyacid anions (Fig. S3), and their integrated COHP (ICOHP) of different $\mathrm{Pb}-\mathrm{O}$ bonds were calculated by the energy integral below Femi level, which is a direct measure of the strength of the oxygen bridge to $\mathrm{Pb}$ sites. The more negative ICOHP means the stronger $\mathrm{Pb}-\mathrm{O}$ bond, and therefore, the favored formation of $\mathrm{XO}-\mathrm{Pb}$ bonds between $\mathrm{CsPbI}_{2} \mathrm{Br}$ and oxyacid anion. From Fig. 1b, it is clear that the interactions of these oxyacid anions with $\mathrm{CsPbI}_{2} \mathrm{Br}$ decrease in order of $\mathrm{SiO}_{3}{ }^{2-}>\mathrm{PO}_{4}{ }^{3-}>\mathrm{CO}_{3}{ }^{2-}>\mathrm{SO}_{4}{ }^{2-}>\mathrm{NO}_{3}{ }^{-}$. 
(a)
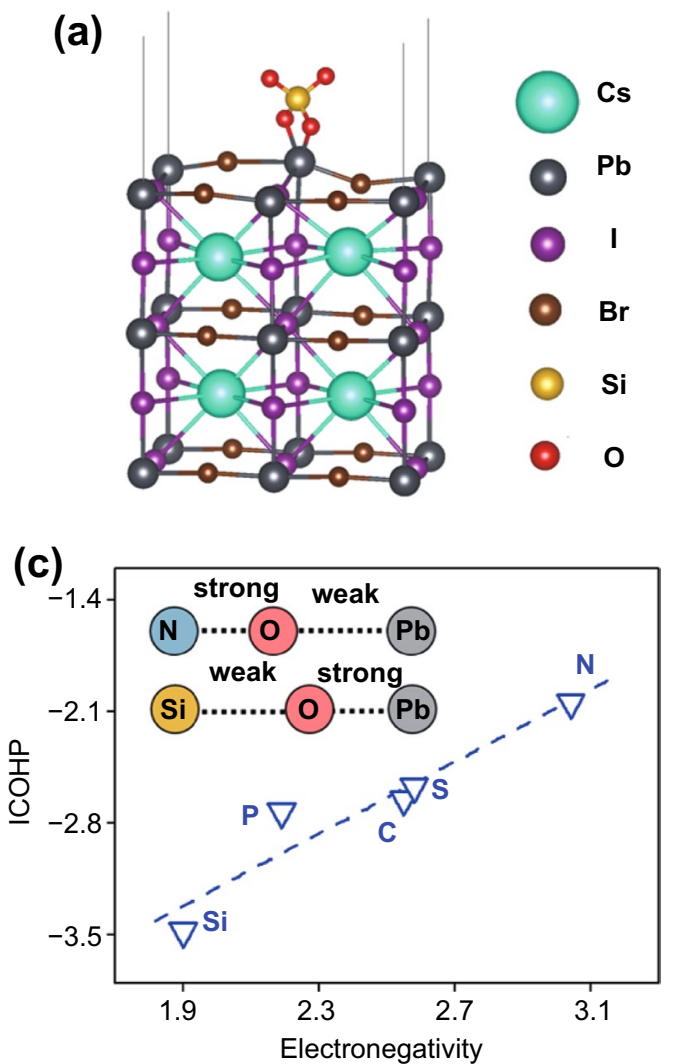

(b)

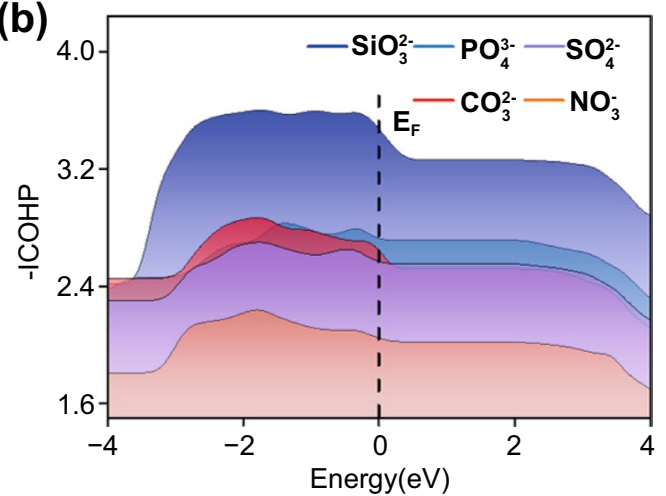

(d)

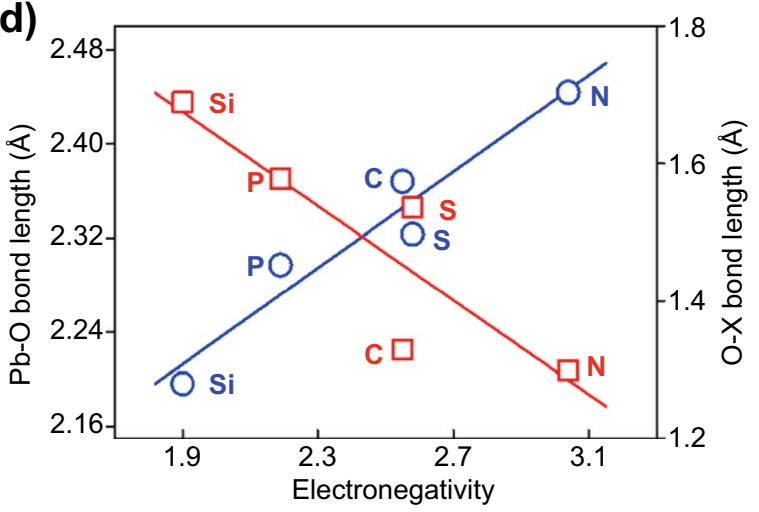

Fig. 1 a Optimized structure of $\mathrm{CsPbI}_{2} \mathrm{Br}(001)$ surface with $\mathrm{SiO}_{3}{ }^{2-}$ adsorbed, where two $\mathrm{O}$ atoms in $\mathrm{SiO}_{3}{ }^{2-}$ bind with $\mathrm{Pb}$ site. b Integrated crystal orbital Hamilton population (ICOHP) between $\mathrm{Pb}$ site and $\mathrm{O}$ atom in the oxyacid anions. More negative ICOHP means the stronger bond strength of $\mathrm{Pb}-\mathrm{O}$ bond. $\mathbf{c}$ Relationship for ICOHP of the $\mathrm{Pb}-\mathrm{O}$ bond on $\mathrm{CsPbI}_{2} \mathrm{Br}(001)$ surface with different oxyacid anions adsorbed as a function of electronegativity of central element $X(X=N, S, C, P, S i)$. d Relationships of the bond lengths of the $X-O(X=N, S, C, P, S i)$ and $\mathrm{Pb}-\mathrm{O}$ bonds on $\mathrm{CsPb}_{2} \mathrm{Br}(001)$ surface with different oxyacid anions as function of electronegativity of central element $\mathrm{X}$. There is a trade-off between the lengths of $\mathrm{X}-\mathrm{O}$ and $\mathrm{Pb}-\mathrm{O}$ bonds in terms of the electronegativity of central atoms

We then scaled the ICOHP of different $\mathrm{Pb}-\mathrm{O}$ bonds with the electronegativity of the central element $\mathrm{X}(\mathrm{X}=\mathrm{C}, \mathrm{N}, \mathrm{Si}, \mathrm{P}, \mathrm{S})$ in different oxyacid anions and observed a linear relationship (Fig. 1c). The ICOHP of the $\mathrm{Pb}-\mathrm{O}$ bond becomes more negative with the decrease in electronegativity of central atoms, meaning that the stronger interaction of oxyacid anion with $\mathrm{CsPb}_{2} \mathrm{Br}$ surface. In principle, the electronegativity determines the ability of central element $\mathrm{X}$ to attract electrons [36]. The central element $X$ with a smaller electronegativity would attract less electrons from the $\mathrm{O}$ atom in the oxyacid anion, causing a weaker $\mathrm{X}-\mathrm{O}$ bond; thus, the $\mathrm{O}$ atom can provide more electrons to bind with cationic $\mathrm{Pb}$ site, giving a stronger $\mathrm{Pb}-\mathrm{O}$ bond. The charge density analysis also verifies that the more electrons accumulate on the two $\mathrm{O}$ atoms of oxysalts as the electronegativity of the central element $\mathrm{X}$ is small (Fig. S4). This can also be understood by the bond order conservation principle, i.e., the less the electrons of an atom distribute over the bonds to the neighboring atom, the more each of these bonds strengthens. The bond strength changes of the $\mathrm{X}-\mathrm{O}$ and $\mathrm{Pb}-\mathrm{O}$ bonds on $\mathrm{CsPbI}_{2} \mathrm{Br}$ surface with the electronegativity are further demonstrated by the opposite change trends of the $\mathrm{X}-\mathrm{O}$ and $\mathrm{Pb}-\mathrm{O}$ bond lengths (Fig. 1d). Hence, the electronegativity of the central element in oxyacid anion is expected to serve as a good descriptor to assess the strength of the chemical bond between oxysalt and perovskite.

\subsection{Experimental Characterization of the Interaction between $\mathrm{CsPbI}_{2} \mathrm{Br}$ Perovskite and Oxysalts}

The bonding behavior of oxysalt/perovskite interface was subsequently characterized by Fourier-transform infrared (FTIR) and Raman spectroscopy. The insensitivity of inorganic $\mathrm{CsPbI}_{2} \mathrm{Br}$ to vibrational spectrum made it suitable for analyzing the surface adsorption configuration 
of oxyacid anions. Diagnostic asymmetric stretch $\left(v_{\text {as }}\right)$ of oxyacid anions generally appears at low-frequency region with the wavenumbers in the range of $900 \sim 1500 \mathrm{~cm}^{-1}$, while the symmetric stretch $\left(v_{\mathrm{s}}\right)$ is absent in FTIR spectra because of the unchanged dipole moment of the symmetric anions [37-46]. As shown in Fig. 2a, all the oxysalt-CsP$\mathrm{bI}_{2} \mathrm{Br}$ samples exhibited FTIR shift of asymmetric stretching of oxysalts compared to the pure samples without perovskite. Raman spectra of Fig. 2b also present smaller wavenumbers of $v_{\text {as }}$ for the samples with $\mathrm{CsPbI}_{2} \mathrm{Br}$ perovskite, in spite of the less sensitive asymmetric stretch of oxysalts. Of most significance is that the trend of $v_{\text {as }}$ $\operatorname{shift}\left(\Delta v_{\text {as }}\right)$ in both FTIR and Raman spectrum exhibits a good linear relationship with respect to electronegativity values (Fig. 2c, d). The small $\Delta v_{\text {as }}$ of nitrate sample spectrum indicates its unchanged configuration after contacting with perovskites, probably because of the low probability of forming $\mathrm{O}-\mathrm{M}$ bond ( $\mathrm{M}$ represents $\mathrm{Pb}$ or $\mathrm{Cs}$ ). Among a serious of inorganic anions, silicate group undergoes the greatest $\Delta v_{\text {as }}$ values, which again confirms the favorable chemical bonding of $\mathrm{O}$ atoms with $\mathrm{Cs}$ or $\mathrm{Pb}$ sites to form $\mathrm{Si}-\mathrm{O}-\mathrm{M}$ bond. As shown in Fig. S5, the $v_{\text {as }}$ band of silicate shifts from $\sim 1021 \mathrm{~cm}^{-1}$ for pure silicate to $\sim 965 \mathrm{~cm}^{-1}$ for silicate- $\mathrm{PbI}_{2}, \sim 972 \mathrm{~cm}^{-1}$ for silicate-CsI and $\sim 951 \mathrm{~cm}^{-1}$ for silicate- $\mathrm{CsPbI}_{2} \mathrm{Br}$ samples, respectively, which illustrate the existence of both $\mathrm{Pb}-\mathrm{O}-\mathrm{Si}$ and $\mathrm{Cs}-\mathrm{O}-\mathrm{Si}$ bonds in these samples [41]. The decrease in wavenumber in FTIR and Raman spectra implies the reduced electron density and spatial elongation of $\mathrm{X}-\mathrm{O}$ bonds at the expense of bonding with $\mathrm{Pb}$ or $\mathrm{Cs}$ cations. These experimental observations are well consistent with our theoretical simulations that the weak $\mathrm{X}-\mathrm{O}$ bonds can strengthen the $\mathrm{O}-\mathrm{Pb}$ interaction and may subsequently lead to better surface passivation.

To assess the electronic property of the oxysalt/perovskite interface, we measured steady-state photoluminescence (PL) and time-resolved photoluminescence (TRPL) decay of $\mathrm{CsPbI}_{2} \mathrm{Br}$ perovskite films deposited on oxysalt/glass substrates. A blue excitation light of $380 \mathrm{~nm}$ was irradiated from the glass side for all samples,
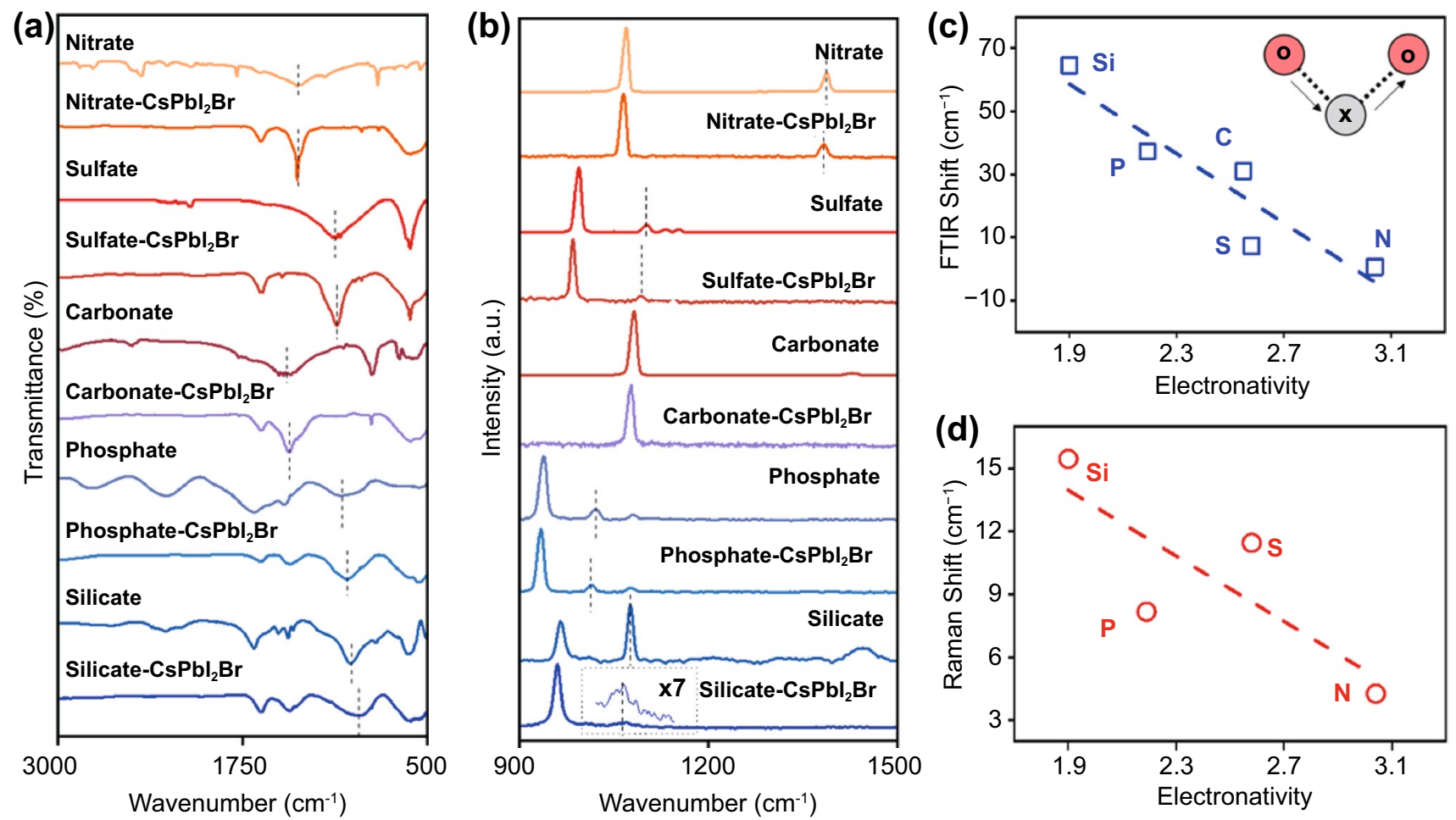

Fig. 2 a FTIR spectra and $\mathbf{b}$ Raman of oxysalts powders without and with perovskite components. The asymmetric stretch $\left(v_{\text {as }}\right)$ peaks of oxysalts are highlighted by dotted lines. Oxysalt and oxysalt $-\mathrm{CsPb}_{2} \mathrm{Br}$ represent the pure oxysalt and the mixture of oxysalt and CsPbI ${ }_{2} \mathrm{Br}$ perovskite, respectively. The Raman asymmetric stretch peak of the mixture of silicate and $\mathrm{CsPbI}_{2} \mathrm{Br}$ is magnified 7 times. Shifts of $\mathbf{c}$ FTIR asymmetric stretch signals and $\mathbf{d}$ Raman asymmetric stretch bands of oxyacid anions by compositing with $\mathrm{CsPb}_{2} \mathrm{Br}$ perovskites as a function of electronegativity. The inset image is the schematic of asymmetric stretching of $\mathrm{O}-\mathrm{X}-\mathrm{O}$ structure for oxyacid anions $(\mathrm{X}=\mathrm{N}, \mathrm{S}, \mathrm{C}, \mathrm{P}, \mathrm{Si})$ 
which has a small penetration depth on perovskites. As shown in Fig. 3a, the PL intensity of nitrate, sulfate, carbonate, phosphate and silicate films is about 1.35, 1.78, 2.57, 3.62 and 4.71 times larger than that on bare glass, indicative of the considerably suppressed interfacial nonradiative recombination by contacting with oxysalts. TRPL curves of the samples were fitted by a biexponential equation to obtain the photocarrier lifetimes (Fig. 3b and Table S1). The fast and slow decay time constants are typically related to charge trapping process and carrier recombination process, respectively [47]. For the pristine $\mathrm{CsPbI}_{2} \mathrm{Br}$ film, the fast decay lifetime is $4.02 \mathrm{~ns}$ and the slow decay lifetime is $15.65 \mathrm{~ns}$, while their fractions are $51 \%$ and $49 \%$, respectively, highlighting the important role of charge trapping procedure of as-fabricated $\mathrm{CsPbI}_{2} \mathrm{Br}$ films. $\mathrm{CsPbI}_{2} \mathrm{Br}$ films with oxysalts passivation displayed a longer carrier lifetime compared to the pristine sample. Among all the oxysalt passivators, silicate anions improved the best and longest carrier lifetime, delivering a fast decay lifetime of $5.90 \mathrm{~ns}(38 \%)$ and a slow decay lifetime of $31.99 \mathrm{~ns}(62 \%)$. This suggests that the oxysalt passivators can effectively inhibit the presence of carrier scavengers from interfacial defects.

\subsection{Photovoltaic Performance of Oxysalt Passivated $\mathrm{CsPbI}_{2} \mathrm{Br}$ Devices}

Solar cell devices were then fabricated with a configuration of indium tin oxide (ITO) glass /tin (IV) oxide $\left(\mathrm{SnO}_{2}\right)$ / $\mathrm{CsPbI}_{2} \mathrm{Br} /$ poly(3-hexylthiophene-2,5-diyl) (P3HT)/Ag in this study (Fig. S6). To simplify the fabrication procedure of oxysalts passivated PSCs, we directly added oxysalts in
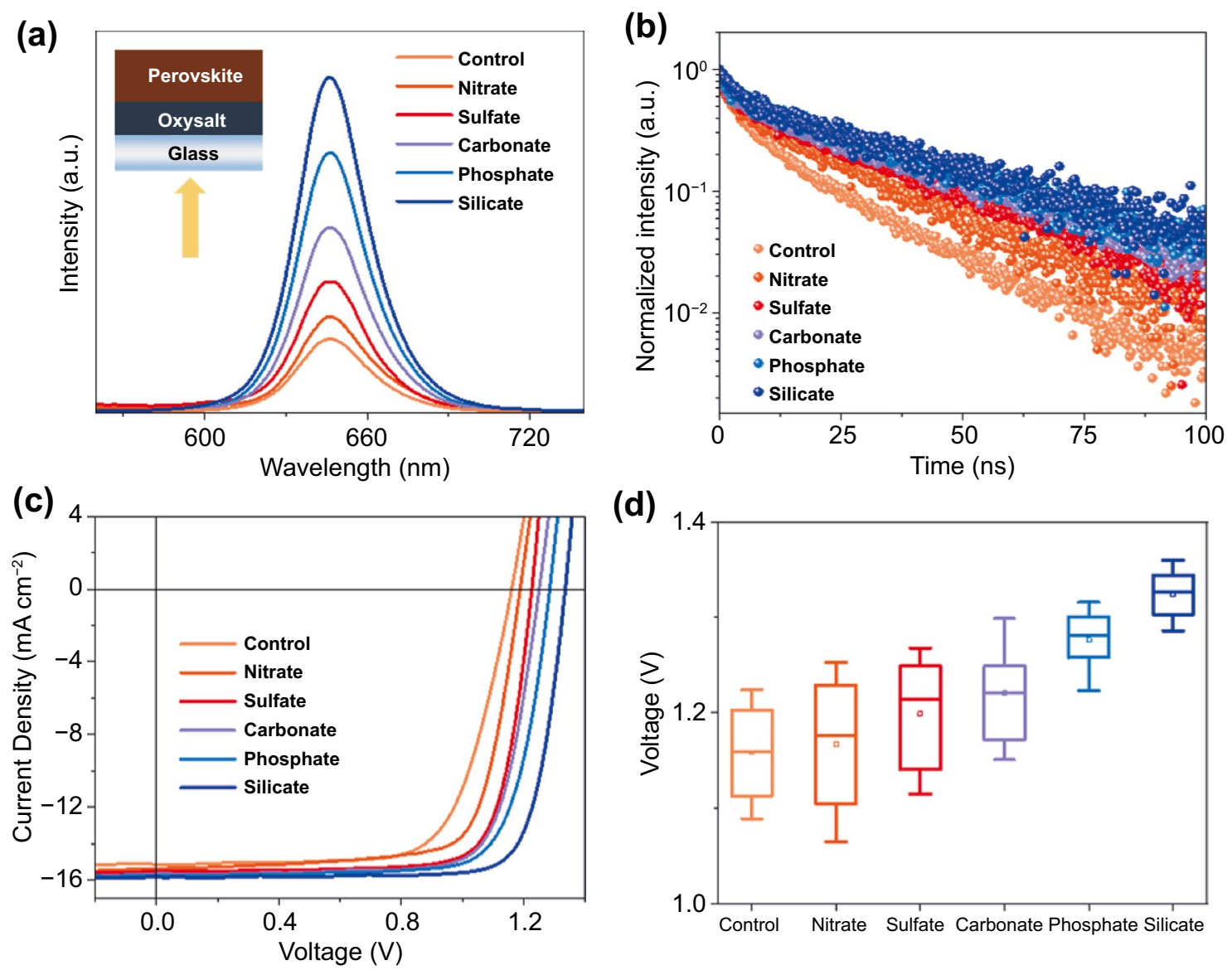

Fig. 3 a Steady-state PL and $\mathbf{b}$ TRPL decay spectra of $\mathrm{CsPbI}_{2} \mathrm{Br}$ perovskite films without and with oxysalt passivation layer. Inset is the schematic of the PL measurement of the perovskite films. The excitation light of was irradiated from the glass side for the PL tests. $\mathbf{c} J-\mathrm{V}$ curves and d $V_{\mathrm{OC}}$ distribution of $\mathrm{CsPbI}_{2} \mathrm{Br}$ solar cells without and with oxysalt passivation. For each kind of device, the solid transverse lines in the boxes are the average PCEs analyzed from 20 individual devices, and the error bars show the highest and lowest PCE values 
the $\mathrm{SnO}_{2}$ colloidal aqueous solution before spin coating. The concentration of all oxysalts used in this work is $0.05 \mathrm{M}$ with the molar ratio of silicate to $\mathrm{SnO}_{2}$ to be $1: 4$, if no specified. As shown in Fig. 3c and Table S2, all solar cell devices with oxysalts showed improved photovoltaic performance with the major contributor of the open-circuit voltage $\left(V_{\mathrm{OC}}\right)$. In principle, $V_{\mathrm{OC}}$ is a measure of quasi-Fermi level splitting of working device that is uplifted by population of charge carriers separately in the conduction band and valence band [20]. The passivation of defective sites generally reduces the non-radiative recombination and thus produces higher density of photogenerated charges, larger quasi-Fermi level splitting as well as improved $V_{\mathrm{OC}}$ values. As expected, the average $V_{\mathrm{OC}}$ of control, nitrate, sulfate, carbonate, phosphate and silicate passivated devices is $\sim 1.15,1.18,1.21,1.22$, 1.28 and $1.33 \mathrm{~V}$, respectively (Fig. 3d). As shown in Fig. S7, the average PCE of control, nitrate, sulfate, carbonate, phosphate and silicate passivated devices is $12.66 \%, 13.37 \%$, $14.04 \%, 14.86 \%, 15.60 \%$ and $16.63 \%$, respectively, confirming the good passivation effect of oxysalts. More importantly, the PL, TRPL and J-V results again support our theoretical predications that low electronegative central atoms of oxysalts can provide better chemical bonding and defect passivation for halide perovskites. Moreover, cations may also passivate perovskite surface and deliver PCE improvement of perovskite solar cells. We then fabricated $\mathrm{CsPbI}_{2} \mathrm{Br}$ solar cells by using $\mathrm{NaI}, \mathrm{KI}, \mathrm{Na}_{2} \mathrm{CO}_{3}$ and $\mathrm{K}_{2} \mathrm{CO}_{3}$ as passivation materials. As shown in Fig. S8, we found that both $\mathrm{Na}^{+}$and $\mathrm{K}^{+}$improved the device performance slightly. Contrastingly, carbonate passivated $\mathrm{CsPbI}_{2} \mathrm{Br}$ devices showed a much more improved PCE. So, we inferred that the oxyacid anions play a critical role in improving device performance.

Opto-electrical characteristics of $\mathrm{SnO}_{2}$ layers and top perovskite layers should be underlying influential factors for device performance, we therefore characterized their physical and structural properties with and without silicate. Firstly, we used X-ray photoelectron spectroscopy (XPS) and $\mathrm{X}$-ray diffraction (XRD) to check the existence of sodium silicate in $\mathrm{SnO}_{2}$ films. Obviously, $\mathrm{Na}$ and $\mathrm{Si}$ signals were observed from the composite film, as shown in Fig. S9. In contrast, the pristine $\mathrm{SnO}_{2}$ film showed no Na and $\mathrm{Si}$ signals. As shown in Fig. S10, diffraction peaks of $\mathrm{Na}_{2} \mathrm{SiO}_{3}$ were observed for the silicate- $\mathrm{SnO}_{2}$ sample, verifying the crystalline phase of solid-state $\mathrm{Na}_{2} \mathrm{SiO}_{3}$ (PDF\# 16-0818). As expected, both $\mathrm{SnO}_{2}$ layers have uniform morphology and high transmittance in the visible region on ITO substrates
(Figs. S11 and S12). In an effort to assess the morphology of as-prepared $\mathrm{SnO}_{2}$ films, atomic force microscope (AFM) imaging was performed. As shown in Fig. S13, both films exhibited a smooth surface but the roughness of the silicate$\mathrm{SnO}_{2}$ film $(5.95 \mathrm{~nm})$ is larger than that $(1.72 \mathrm{~nm})$ of the $\mathrm{SnO}_{2}$ film. To evaluate the electrical conductivity of these films, we fabricated devices structured as $\mathrm{ITO} / \mathrm{SnO}_{2} / \mathrm{Ag}$ and ITO/Silicate- $\mathrm{SnO}_{2} / \mathrm{Ag}$ and measured the dark J-V curves. In order to avoid the probably direct contact between Ag and ITO, we improved the films thickness of $\mathrm{SnO}_{2}$ layers by spin coating the precursor solution for six cycles. As illustrated in Fig. S14, rectifying behaviors were observed for both ITO/ $\mathrm{SnO}_{2} / \mathrm{Ag}$ and ITO/Silicate- $\mathrm{SnO}_{2} / \mathrm{Ag}$ devices. The conductivity of silicate- $\mathrm{SnO}_{2}$ film was observed to be closed to that of pristine $\mathrm{SnO}_{2}$ film, confirming that the introduction of silicate did not affect the electrical conductivity of $\mathrm{SnO}_{2}$ films. After deposition of $\mathrm{CsPbI}_{2} \mathrm{Br}$ films, strong (100) and (200) diffraction peaks appear for both samples as shown in the XRD patterns of Fig. S15 [28]. In addition, scanning electronic microscopy (SEM) images in Fig. S16 show the similar compact and uniform morphology of $\mathrm{CsPbI}_{2} \mathrm{Br}$ films on both substrates. Therefore, the photovoltaic performance enhancement should be attributed to the interfacial passivation rather than the structural change of $\mathrm{SnO}_{2}$ and perovskite layer.

The electronic band structure of $\mathrm{SnO}_{2}$ films with silicate was investigated by ultraviolet photoelectron spectroscopy (UPS). Figures 4a and S17 depict the secondary electron cutoff and the valence band region of UPS spectra for $\mathrm{SnO}_{2}$ layers without and with silicate. The concentration of silicate anions in $\mathrm{SnO}_{2}$ solution was varied from 0.012 to $0.1 \mathrm{M}$. By increasing the content of silicate, the valance band maximum (VBM) of $\mathrm{SnO}_{2}$ layers initially upshifts from -7.75 to $-7.64 \mathrm{eV}$ for $0.012 \mathrm{M}$ sample and then gradually downshifts to $-7.91 \mathrm{eV}$ at $0.1 \mathrm{M}$ of silicate. The optical bandgap $\left(E_{\mathrm{g}}\right)$ of $\mathrm{SnO}_{2}$ and sodium silicate was determined to be 3.39 and $3.75 \mathrm{eV}$ by UV-vis spectra, respectively (Fig. 4b). For the $0.05 \mathrm{M}$ sample, the molar ratio of $\mathrm{Si}$ to $\mathrm{Sn}$ is $\sim 1: 4$, suggesting that a silicate shell should be favored on tin oxide particles. The thickening of silicate layers is likely to uplift the conduction band minimum (CBM) gradually to the value of bulk sodium silicate itself and better align the band structure of $\mathrm{SnO}_{2}$ /perovskite interface at certain oxysalt contents (Fig. 4c) [48, 49]. PSCs with varied concentration of silicate were also fabricated, and the $\mathrm{J}-\mathrm{V}$ results are shown in Fig. $4 \mathrm{~d}$ and Table $\mathrm{S} 3$. The addition of silicate persistently 

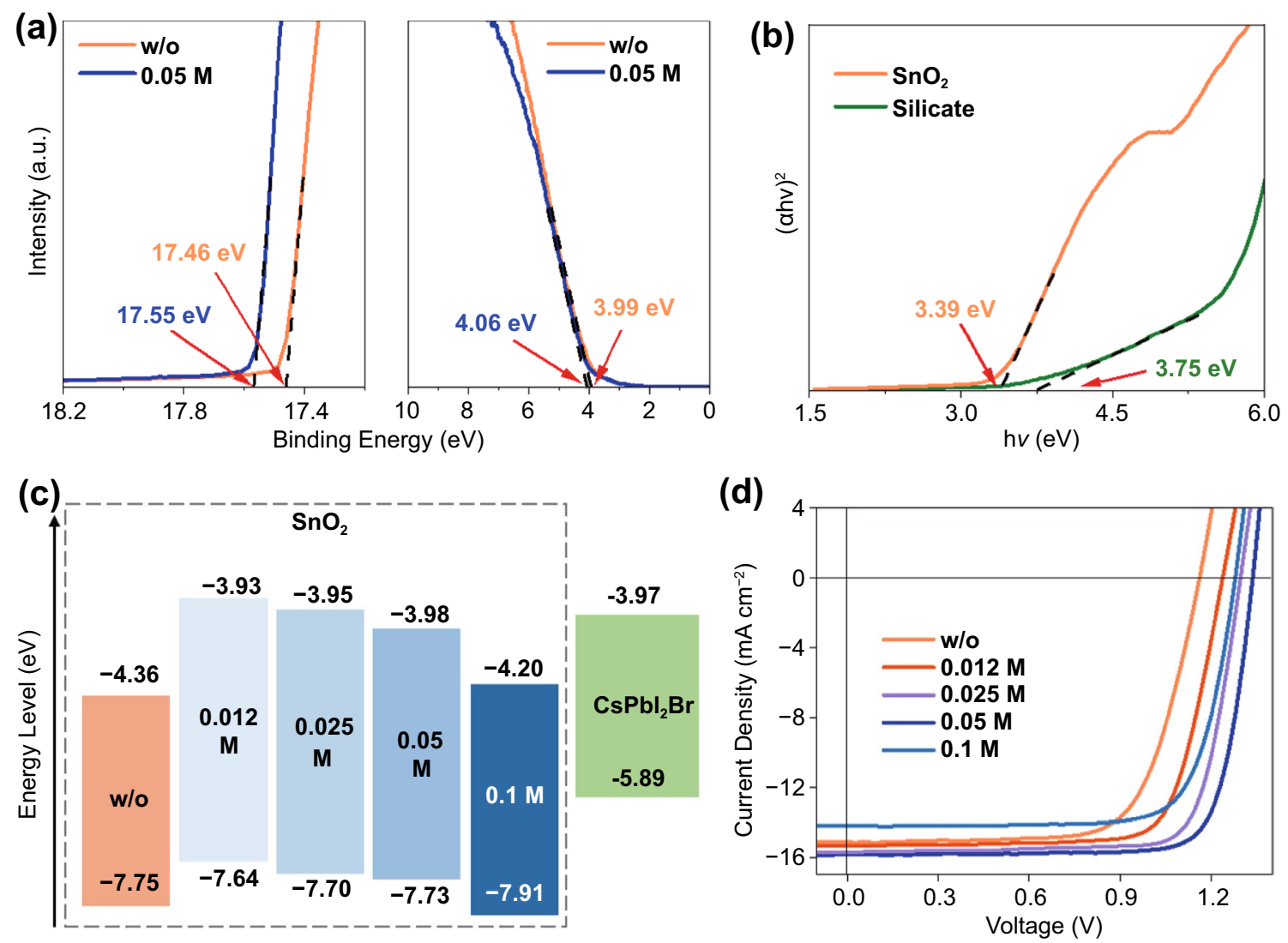

Fig. 4 a Photoemission cutoff spectra (left panel) and valence band (VB) structure (right panel) of $\mathrm{SnO}_{2}$ films without and with silicate. The dotted lines indicate the secondary electron cutoff position and the valance band onset of the films obtained by linear extrapolating the binding energy edge to the baseline. b Tauc plots of the pure $\mathrm{SnO}_{2}$ and silicate powders. c Energy level scheme of the charge transport and perovskite layers in this work. $\mathbf{d ~ J}-\mathrm{V}$ curves of typical $\mathrm{CsPb}_{2} \mathrm{Br}$ solar cells with different concentrations of silicate anions in $\mathrm{SnO}_{2}$ layers

improves the $V_{\mathrm{OC}}$ of PSCs with the silicate concentration up to $0.1 \mathrm{M}$, whereas excess oxysalts would give rise to very thick silicate shell, impede charge collection and result in low short-circuit current density $\left(J_{\mathrm{SC}}\right)$ values.

After optimization of experimental parameters, the champion silicate devices based on $\mathrm{CsPbI}_{2} \mathrm{Br}$ perovskite yielded a high PCE of $17.26 \%$ with a $J_{\text {SC }}$ of $15.86 \mathrm{~mA} \mathrm{~cm}^{-2}$, an open-circuit voltage $\left(V_{\mathrm{OC}}\right)$ of $1.36 \mathrm{~V}$ and a fill factor (FF) of 0.80 (Fig. 5a). In contrast, the control device without silicate delivered a PCE of $13.52 \%$ with a $\mathrm{J}_{\mathrm{SC}}$ of $15.20 \mathrm{~mA} \mathrm{~cm}^{-2}$, an open-circuit voltage $\left(V_{\mathrm{OC}}\right)$ of $1.22 \mathrm{~V}$ and a fill factor (FF) of 0.73 . The $\mathrm{J}_{\mathrm{SC}}$ values from $\mathrm{J}-\mathrm{V}$ tests match well with the integrated $J_{\mathrm{SC}}$ from the external quantum efficiency spectra (EQE, Fig. S18). To the best of our knowledge, our device performance is among the highest $\mathrm{PCEs}$ for $\mathrm{CsPbI}_{2} \mathrm{Br}$ solar cells reported to date (Table S4). Noteworthy, silicate passivated device undergoes negligible hysteresis under different scan directions, suggesting reduced electronic trap states or ion migration at the interface. In addition, we also monitored the stabilized power output of our champion device under maximum power point (MPP) condition. As shown in Fig. 5b, a stabilized PCE of $17.01 \%$ was obtained together with a $\mathrm{J}_{\mathrm{SC}}$ of $15.63 \mathrm{~mA} \mathrm{~cm}^{-2}$ for nearly $300 \mathrm{~s}$ under a bias of $1.09 \mathrm{~V}$. The reproducibility of PSC devices was evaluated by 20 individual devices for each sample that the average PCE boosted from $12.66 \pm 0.49 \%$ for the control device to $16.63 \pm 0.42 \%$ (Fig. S19).

Charge recombination behavior of the PSC devices was then evaluated by light intensity-dependent $V_{\mathrm{OC}}$ measurement. As shown in Fig. 5c, the slope (kT/q) of $V_{\mathrm{OC}}$ versus the natural logarithm of light intensity for the control and silicate devices was estimated to be 1.89 and $1.23 \mathrm{kT} / \mathrm{q}$, respectively. This discrepancy indicates that the trap-induced charge recombination was effectively suppressed in the silicate device [50]. Transient photovoltage (TPV) curves of 

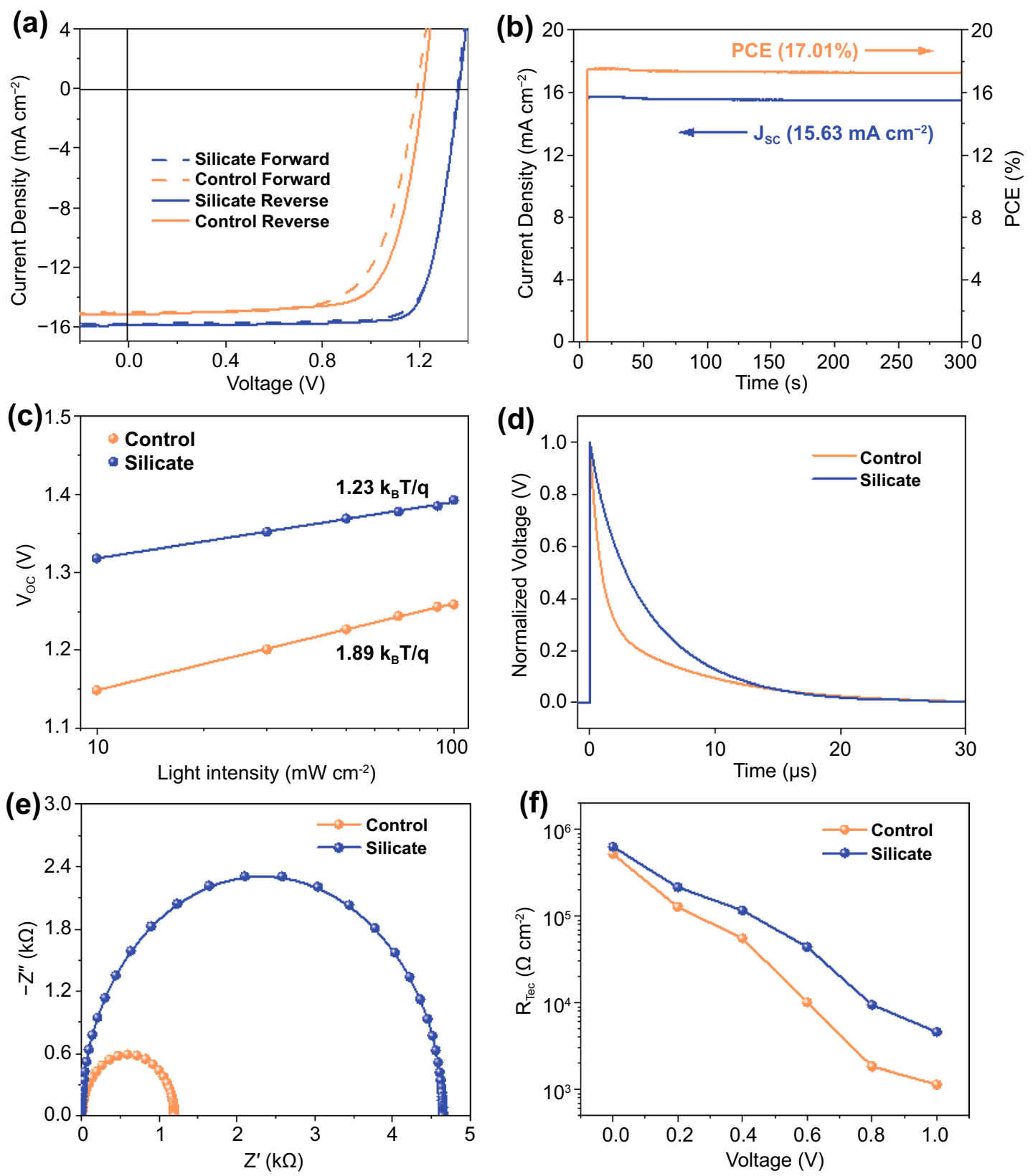

Fig. 5 a J-V curves of champion PSC devices measured under simulated AM 1.5G irradiation at different scan directions. b Steady-state power output (blue) and current density (red) of the champion cell measured at maximum power point (MPP) voltage as a function of time. $\mathbf{c} V_{\mathrm{OC}}$ values of the control and silicate passivated $\mathrm{CsPb}_{2} \mathrm{Br}$ device as a function of light intensity. $\mathbf{d}$ Transient photovoltage measurements for control and silicate passivated PSCs. e Nyquist plots of control and silicate passivated $\mathrm{CsPbI}_{2} \mathrm{Br}$ devices under dark with a bias voltage of $1.0 \mathrm{~V}$. f Dependence of $R_{\text {rec }}$ on applied bias voltage for $\mathrm{CsPbI}_{2} \mathrm{Br}$ device with and without silicate passivation. $R_{\text {rec }}$ was obtained by fitting the EIS spectra at different voltages

$\mathrm{CsPbI}_{2} \mathrm{Br}$ solar cells were recorded by oscilloscope under the excitation of an attenuated laser pulses. The carrier recombination lifetimes of control and silicate devices are 1.7 and $4.4 \mu \mathrm{s}$, respectively, again confirming the suppressed charge recombination rate in devices. To further evaluate the interfacial carrier dynamic properties in $\mathrm{CsPbI}_{2} \mathrm{Br}$ devices, electrochemical impedance spectroscopy (EIS) was carried under different bias voltages in dark condition [51]. Figure $5 \mathrm{e}$ presented the Nyquist plots of control and silicate $\mathrm{CsPbI}_{2} \mathrm{Br}$ solar cells. The recombination resistance $\left(R_{\mathrm{rec}}\right)$ of 
the silicate passivated $\mathrm{CsPbI}_{2} \mathrm{Br}$ solar cell is about 4 times larger than that of the $\mathrm{SnO}_{2}$-based $\mathrm{CsPbI}_{2} \mathrm{Br}$ device at the bias voltage of $1.0 \mathrm{~V}$. After fitting the measured data under different bias voltages, it is clear that the silicate passivated devices exhibited higher $R_{\text {rec }}$ value than that of the control one, indicating its slower recombination rate (Fig. 5f). We further estimated the trap density of electron-only device structured as $\mathrm{ITO} / \mathrm{SnO}_{2} / \mathrm{CsPbI}_{2} \mathrm{Br} / \mathrm{PCBM} / \mathrm{Ag}$ by spacecharge-limited-current (SCLC) measurements (Fig. S20). The trap density $\left(N_{\text {defects }}\right)$ is calculated by Eq. 1 :

$N_{\text {defects }}=\frac{2 \varepsilon \varepsilon_{0} V_{\mathrm{TFL}}}{e L^{2}}$

(where e is the electron charge, $L$ is the thickness of the perovskite layer, $\varepsilon_{0}$ and $\varepsilon$ are the vacuum permittivity and the relative dielectric constant, and $V_{\mathrm{TFL}}$ is the onset voltage of the trap-filled limited region [52]). The defect density of the control and silicate passivated perovskite films was calculated to be $3.03 \times 10^{16}$ and $2.09 \times 10^{16} \mathrm{~cm}^{-3} \mathrm{~s}$, respectively, which should be derived from the defect passivation of perovskite/ETL interface.

\subsection{Device Stability Study}

Finally, we evaluated the long-term device stability with a device structure of ITO/ $\mathrm{SnO}_{2} / \mathrm{CsPbI}_{2} \mathrm{Br} / \mathrm{P} 3 \mathrm{HT} / \mathrm{Au}$ against light illumination, heat and humidity. We monitored the operational stability of the $\mathrm{CsPbI}_{2} \mathrm{Br}$ solar cells under continuous AM 1.5G illumination in a nitrogen-filled glovebox (Fig. S21). The efficiency of control device dropped rapidly to $\sim 60 \%$ of its initial value after $500 \mathrm{~h}$, whereas the silicate passivated device still retained $\sim 92 \%$ of its initial value. The thermal stability of the $\mathrm{CsPbI}_{2} \mathrm{Br}$ solar cells was recorded by heating the devices at $85{ }^{\circ} \mathrm{C}$ in a $\mathrm{N}_{2}$-filled glovebox (Fig. S22). Compared to the nearly $30 \%$ loss of PCE for the control device, the silicate passivated $\mathrm{CsPbI}_{2} \mathrm{Br}$ solar cells maintained $\sim 90 \%$ of its initial efficiency after $240 \mathrm{~h}$. As illustrated in Fig. S23, the moisture stability of the silicate passivated $\mathrm{CsPbI}_{2} \mathrm{Br}$ solar cells was also improved that the retained PCEs of control and silicate device are $~ 50 \%$ and $\sim 87 \%$, respectively, after stored in ambient air with $15 \pm 3 \%$ humidity for $1440 \mathrm{~h}$. The passivation of defective surface may suppress the mass transport of perovskites and impose instructive effect on device durability.
Table 1 Photovoltaic parameters of the champion PSCs based on different perovskite compositions

\begin{tabular}{llllll}
\hline Composition & Passivation & $\begin{array}{l}J_{\text {SC }}(\mathrm{mA} \\
\left.\mathrm{cm}^{-2}\right)\end{array}$ & $V_{\mathrm{OC}}(\mathrm{V})$ & FF & PCE (\%) \\
\hline $\mathrm{CsPbI}_{2} \mathrm{Br}$ & w/o & 15.20 & 1.22 & 0.73 & 13.52 \\
& Silicate & 15.86 & 1.36 & 0.80 & 17.26 \\
$\mathrm{FAPbI}_{3}$ & w/o & 23.71 & 1.07 & 0.71 & 18.20 \\
& Silicate & 24.14 & 1.13 & 0.79 & 21.62 \\
$\mathrm{MAPbI}_{3}$ & w/o & 21.99 & 1.09 & 0.73 & 17.50 \\
& Silicate & 22.36 & 1.14 & 0.80 & 20.39 \\
\hline
\end{tabular}

Devices were measured under simulated AM $1.5 \mathrm{G}$ irradiation at the reverse scan

\section{Conclusions}

In summary, we have systematically investigated the central atom effect of inorganic oxysalts on the passivation of lead halide perovskite and elucidated the central-atomdependent-passivation mechanism that local the interactions between $\mathrm{O}$ from oxysalt and metal cations from perovskite are negatively correlated with the electronegativity of central atoms. Such phenomenon can be unambiguously described by the bond order conservation principle. By using silicate passivation, we achieved a high PCE of $17.26 \%$ for $\mathrm{CsPbI}_{2} \mathrm{Br}$ solar cell devices, which is among the best of this class of devices. We also applied such silicate passivation strategy into $\mathrm{FAPbI}_{3}$ and $\mathrm{MAPbI}_{3}$ devices (Figs. S24 and S25). Obviously, the $\mathrm{FAPbI}_{3}$-based devices exhibited an improved PCE from 18.20 to $21.62 \%$, and the $\mathrm{MAPbI}_{3}$-based devices showed an improved PCE from 17.50 to $20.39 \%$, corroborating the versatility of our strategy in organic-inorganic perovskite systems (Table 1). Our findings shed light on the basic understanding about the chemical adsorption and bond formation of perovskite surface and also provide the guidelines for designing functional interface materials toward the prosperous optoelectronic application of perovskite devices.

Acknowledgements Ze Qing Lin and Hui Jun Lian contributed equally to this work. This work was financially supported by National Natural Science Fund for Excellent Young Scholars (52022030), International (Regional) Cooperation and Exchange Projects of the National Natural Science Foundation of China (51920105003), National Natural Science Fund for Distinguished Young Scholars (51725201), National Ten Thousand Talent Program for Young Top-notch Talent, National Natural Science Foundation of China (51902185, 51972111), Innovation Program of Shanghai Municipal Education Commission (E00014) and Shanghai Engineering Research Center of Hierarchical Nanomaterials 
(18DZ2252400). The authors also thank the Frontiers Science Center for Materiobiology and Dynamic Chemistry.

Open Access This article is licensed under a Creative Commons Attribution 4.0 International License, which permits use, sharing, adaptation, distribution and reproduction in any medium or format, as long as you give appropriate credit to the original author(s) and the source, provide a link to the Creative Commons licence, and indicate if changes were made. The images or other third party material in this article are included in the article's Creative Commons licence, unless indicated otherwise in a credit line to the material. If material is not included in the article's Creative Commons licence and your intended use is not permitted by statutory regulation or exceeds the permitted use, you will need to obtain permission directly from the copyright holder. To view a copy of this licence, visit http://creativecommons.org/licenses/by/4.0/.

Electronic supplementary material The online version of this article (https://doi.org/10.1007/s40820-021-00683-7) contains supplementary material, which is available to authorized users.

\section{References}

1. S. Yang, S. Chen, E. Mosconi, Y. Fang, X. Xiao et al., Stabilizing halide perovskite surfaces for solar cell operation with wide-bandgap lead oxysalts. Science 365, 473-478 (2019). https://doi.org/10.1126/science.aax3294

2. Y. Hou, E. Aydin, M.D. Bastiani, C. Xiao, F.H. Isikgor et al., Efficient tandem solar cells with solution-processed perovskite on textured crystalline silicon. Science 367, 1135-1140 (2020). https://doi.org/10.1126/science.aaz3691

3. M.M. Lee, J. Teuscher, T. Miyasaka, T.N. Murakami, H.J. Snaith, Efficient hybrid solar cells based on meso-superstructured organometal halide perovskites. Science 338, 643-646 (2012). https://doi.org/10.1126/science.1228604

4. W.S. Yang, J.H. Noh, N.J. Jeon, Y.C. Kim, S. Ryu et al., Highperformance photovoltaic perovskite layers fabricated through intramolecular exchange. Science 348, 1234-1237 (2015). https://doi.org/10.1126/science.aaa9272

5. Y. Wang, M.I. Dar, L.K. Ono, T. Zhang, M. Kan et al., Thermodynamically stabilized $\beta-\mathrm{CsPI}_{3}$-based perovskite solar cells with efficiencies $>18 \%$. Science 365, 591-595 (2019). https://doi.org/10.1126/science.aav8680

6. K. Xiao, R. Lin, Q. Han, Y. Hou, Z. Qin et al., All-perovskite tandem solar cells with $24.2 \%$ certified efficiency and area over $1 \mathrm{~cm}^{2}$ using surface-anchoring zwitterionic antioxidant. Nat. Energy 5, 870-880 (2020). https://doi.org/10.1038/ s41560-020-00705-5

7. National Renewable Energy Laboratory, Best Research-Cell Efficiency Chart; https://www.nrel.gov/pv/assets/pdfs/bestresearch-cell-efficiencies.20200929.pdf

8. T.H. Han, S. Tan, J. Xue, L. Meng, J.W. Lee et al., Interface and defect engineering for metal halide perovskite optoelectronic devices. Adv. Mater. 31, e1803515 (2019). https://doi.org/10.1002/adma.201803515

9. J. Chen, N.G. Park, Causes and solutions of recombination in perovskite solar cells. Adv. Mater. 31, e1803019 (2019). https://doi.org/10.1002/adma.201803019

10. Y. Zhou, Y. Zhao, Chemical stability and instability of inorganic halide perovskites. Energy Environ. Sci. 12, 1495-1511 (2019). https://doi.org/10.1039/C8EE03559H

11. C.M. Wolff, P. Caprioglio, M. Stolterfoht, D. Neher, Nonradiative recombination in perovskite solar cells: the role of interfaces. Adv. Mater. 31, e1902762 (2019). https://doi.org/ 10.1002/adma.201902762

12. J. Song, T. Fang, J. Li, L. Xu, F. Zhang et al., Organic-inorganic hybrid passivation enables perovskite QLEDs with an EQE of 16.48\%. Adv. Mater. 30, e1805409 (2018). https:// doi.org/10.1002/adma.201805409

13. P. Chen, Y. Bai, S. Wang, M. Lyu, J.-H. Yun et al., In situ growth of 2D perovskite capping layer for stable and efficient perovskite solar cells. Adv. Funct. Mater. 28, 1706923 (2018). https://doi.org/10.1002/adfm.201706923

14. Y. Shao, Y. Fang, T. Li, Q. Wang, Q. Dong et al., Grain boundary dominated ion migration in polycrystalline organic-inorganic halide perovskite films. Energy Environ. Sci. 9, 1752-1759 (2016). https://doi.org/10.1039/C6EE0 0413J

15. X. Jiang, F. Wang, Q. Wei, H. Li, Y. Shang et al., Ultra-high open-circuit voltage of tin perovskite solar cells via an electron transporting layer design. Nat. Commun. 11, 1245 (2020). https://doi.org/10.1038/s41467-020-15078-2

16. E.A. Alharbi, A.Y. Alyamani, D.J. Kubicki, A.R. Uhl, B.J. Walder et al., Atomic-level passivation mechanism of ammonium salts enabling highly efficient perovskite solar cells. Nat. Commun. 10, 3008 (2019). https://doi.org/10.1038/ s41467-019-10985-5

17. Q. Wang, X. Zheng, Y. Deng, J. Zhao, Z. Chen et al., Stabilizing the $\alpha$-phase of $\mathrm{CsPbI}_{3}$ perovskite by sulfobetaine zwitterions in one-step spin-coating films. Joule 1, 371-382 (2017). https://doi.org/10.1016/j.joule.2017.07.017

18. M. Kim, S.G. Motti, R. Sorrentino, A. Petrozza, Enhanced solar cell stability by hygroscopic polymer passivation of metal halide perovskite thin film. Energy Environ. Sci. 11, 2609-2619 (2018). https://doi.org/10.1039/C8EE01101J

19. T. Fang, T. Wang, X. Li, Y. Dong, S. Bai et al., Perovskite QLED with an external quantum efficiency of over $21 \%$ by modulating electronic transport. Sci. Bull. 66, 36-43 (2020). https://doi.org/10.1016/j.scib.2020.08.025

20. Y. Shao, Y. Yuan, J. Huang, Correlation of energy disorder and open-circuit voltage in hybrid perovskite solar cells. Nat. Energy 1, 15001 (2016). https://doi.org/10.1038/nenergy. 2015.1

21. P.Y. Gu, N. Wang, A. Wu, Z. Wang, M. Tian et al., An azaacene derivative as promising electron-transport layer for inverted perovskite solar cells. Chem. Asian. J 11, 2135-2138 (2016). https://doi.org/10.1002/asia.201600856 
22. S. Zhang, H. Gu, S.-C. Chen, Q. Zheng, KF-Doped $\mathrm{SnO}_{2}$ as an electron transport layer for efficient inorganic $\mathrm{CsPbI}_{2} \mathrm{Br}$ perovskite solar cells with enhanced open-circuit voltages. J. Mater. Chem. C 9, 4240-4247 (2021). https://doi.org/10.1039/ D1TC00277E

23. A.A. Said, J. Xie, Q. Zhang, Recent progress in organic electron transport materials in inverted perovskite solar cells. Small 15, 1900854 (2019). https://doi.org/10.1002/smll.20190 0854

24. W.Q. Wu, P.N. Rudd, Z. Ni, C.H. Van Brackle, H. Wei et al., Reducing surface halide deficiency for efficient and stable iodide-based perovskite solar cells. J. Am. Chem. Soc. 142, 3989-3996 (2020). https://doi.org/10.1021/jacs.9b13418

25. P. Zhu, S. Gu, X. Luo, Y. Gao, S. Li et al., Simultaneous contact and grain-boundary passivation in planar perovskite solar cells using $\mathrm{SnO}_{2}-\mathrm{KCl}$ composite electron transport layer. Adv. Energy Mater. 10, 1903083 (2019). https://doi.org/10.1002/ aenm.201903083

26. W. Qi, X. Zhou, J. Li, J. Cheng, Y. Li et al., Inorganic material passivation of defects toward efficient perovskite solar cells. Sci. Bull. 65, 2022-2032 (2020). https://doi.org/10.1016/j. scib.2020.07.017

27. Q. Ye, Y. Zhao, S. Mu, F. Ma, F. Gao et al., Cesium lead inorganic solar cell with efficiency beyond $18 \%$ via reduced charge recombination. Adv. Mater. 31, e1905143 (2019). https://doi. org/10.1002/adma.201905143

28. S.S. Mali, J.V. Patil, P.S. Shinde, G. de Miguel, C.K. Hong, Fully air-processed dynamic hot-air-assisted M:CsPbI ${ }_{2} \mathrm{Br}(\mathrm{M}$ : $\mathrm{Eu}^{2+}, \mathrm{In}^{3+}$ ) for stable inorganic perovskite solar cells. Matter 4, 1-19 (2020). https://doi.org/10.1016/j.matt.2020.11.008

29. M. Abdi-Jalebi, Z. Andaji-Garmaroudi, S. Cacovich, C. Stavrakas, B. Philippe et al., Maximizing and stabilizing luminescence from halide perovskites with potassium passivation. Nature 555, 497-501 (2018). https://doi.org/10.1038/ nature 25989

30. T.Y. Wen, S. Yang, P.F. Liu, L.J. Tang, H.W. Qiao et al., Surface electronic modification of perovskite thin film with waterresistant electron delocalized molecules for stable and efficient photovoltaics. Adv. Energy Mater. 8, 1703143 (2018). https:// doi.org/10.1002/aenm.201703143

31. S. Yang, J. Dai, Z. Yu, Y. Shao, Y. Zhou et al., Tailoring passivation molecular structures for extremely small open-circuit voltage loss in perovskite solar cells. J. Am. Chem. Soc. 141, 5781-5787 (2019). https://doi.org/10.1021/jacs.8b13091

32. D. Perez-Del-Rey, D. Forgacs, E.M. Hutter, T.J. Savenije, D. Nordlund et al., Strontium insertion in methylammonium lead iodide: long charge carrier lifetime and high fill-factor solar cells. Adv. Mater. 28, 9839-9845 (2016). https://doi.org/10. 1002/adma.201603016

33. G. Kresse, J. Furthmüller, Efficient iterative schemes for ab initio total-energy calculations using a plane-wave basis set. Phys. Rev. B 54, 11169-11186 (1996). https://doi.org/10. 1103/PhysRevB.54.11169

34. R. Dronskowski, P.E. Blöchl, Crystal orbital hamilton populations (Cohp) —energy-resolved visualization of chemical bonding in solids based on density-functional calculations. J. Phys. Chem. 97, 8617-8624 (1993). https://doi.org/10.1021/ j100135a014

35. J. He, W.-H. Fang, R. Long, O.V. Prezhdo, Bidentate Lewis bases are preferred for passivation of $\mathrm{MAPbI}_{3}$ surfaces: a timedomain ab initio analysis. Nano Energy 79, 105491 (2021). https://doi.org/10.1016/j.nanoen.2020.105491

36. N. Li, S. Tao, Y. Chen, X. Niu, C.K. Onwudinanti et al., Cation and anion immobilization through chemical bonding enhancement with fluorides for stable halide perovskite solar cells. Nat. Energy 4, 408-415 (2019). https://doi.org/10.1038/ s41560-019-0382-6

37. M.K. Trivedi, A.B. Dahryn Trivedi, Spectroscopic characterization of disodium hydrogen orthophosphate and sodium nitrate after biofield treatment. J. Chromatogr. Sep. Tech. 06, 1000282 (2015). https://doi.org/10.4172/2157-7064.10002 82

38. F. Ren, Y. Ding, Y. Leng, Infrared spectroscopic characterization of carbonated apatite: a combined experimental and computational study. J. Biomed. Mater. Res. A 102, 496-505 (2014). https://doi.org/10.1002/jbm.a.34720

39. D. Peak, R.G. Ford, D.L. Sparks, An in situ ATR-FTIR investigation of sulfate bonding mechanisms on goethite. J. Colloid Interface Sci. 218, 289-299 (1999). https://doi.org/10.1006/ jcis.1999.6405

40. H. Sahu, K. Mohanty, Pseudo-first order reaction kinetics and thermodynamic properties study of neem oil esterification using $\mathrm{MgO}$ grafted natural hydroxyapatite. RSC Adv. 6, 8892-8901 (2016). https://doi.org/10.1039/C5RA25095A

41. N. Rahmat, F. Hamzah, N. Sahiron, M. Mazlan, M.M. Zahari, Sodium silicate as source of silica for synthesis of mesoporous SBA-15. IOP Conf. Ser: Mater. Sci. Eng. 133, 012011 (2016). https://doi.org/10.1088/1757-899X/133/1/012011

42. M. Maiberg, T. Hölscher, S. Zahedi-Azad, R. Scheer, Theoretical study of time-resolved luminescence in semiconductors. III. Trap states in the band gap. J. Appl. Phys. 118, 105701 (2015). https://doi.org/10.1063/1.4929877

43. L.J.A. Koster, V.D. Mihailetchi, R. Ramaker, P.W.M. Blom, Light intensity dependence of open-circuit voltage of polymer:fullerene solar cells. Appl. Phys. Lett. 86, 123509 (2005). https://doi.org/10.1063/1.1889240

44. F. Fabregat-Santiago, G. Garcia-Belmonte, I. Mora-Seró, J. Bisquert, Characterization of nanostructured hybrid and organic solar cells by impedance spectroscopy. Phys. Chem. Chem. Phys. 13, 9083-9118 (2011). https://doi.org/10.1039/ C0CP02249G

45. D. Shi, V. Adinolfi, R. Comin, M. Yuan, E. Alarousu et al., Low trap-state density and long carrier diffusion in organolead trihalide perovskite single crystals. Science 347, 519-522 (2015). https://doi.org/10.1126/science.aaa2725

46. K.B. Mabrouk, T.H. Kaouffmann, H. Aroui, M.D. Fontana, Raman study of cation effect on sulfate vibration modes in solid state and in aqueous solutions. J. Raman Spectrosc. 44, 1603-1608 (2013). https://hal.archives-ouvertes.fr/hal-00863 209 
47. T. Uchino, T. Sakka, M. Iwasaki, Interpretation of hydrated states of sodium silicate glasses by infrared and raman analysis. J. Am. Ceram. Soc. 74, 306-313 (1991). https://doi.org/ 10.1111/j.1151-2916.1991.tb06880.x

48. A. Mirzehmet, T. Ohtsuka, S.A. Abd Rahman, T. Yuyama, P. Kruger et al., Surface termination of solution-processed $\mathrm{CH}_{3} \mathrm{NH}_{3} \mathrm{PbI}_{3}$ perovskite film examined using electron spectroscopies. Adv. Mater. 33, e2004981 (2021). https://doi.org/ 10.1002/adma.202004981

49. D. Zhang, C. Liu, K. Li, W. Guo, F. Gao et al., Trappedelectron-induced hole injection in perovskite photodetector with controllable gain. Adv. Optic. Mater. 6, 1701189 (2018). https://doi.org/10.1002/adom.201701189
50. D. Pan, G. Galli, A first principles method to determine speciation of carbonates in supercritical water. Nat. Commun. 11, 421 (2020). https://doi.org/10.1038/s41467-019-14248-1

51. M. Xu, J.P. Larentzos, M. Roshdy, L.J. Criscenti, H.C. Allen, Aqueous divalent metal-nitrate interactions: hydration versus ion pairing. Phys. Chem. Chem. Phys. 10, 4676-4677 (2008). https://doi.org/10.1039/B807090N

52. R.L. Frost, A. López, Y. Xi, A. Granja, R. Scholz et al., Vibrational spectroscopy of the phosphate mineral kovdorskite $\mathrm{Mg}_{2} \mathrm{PO}_{4}(\mathrm{OH}) \cdot 3 \mathrm{H}_{2} \mathrm{O}$. Spectrochim. Acta A 114, 309-315 (2013). https://doi.org/10.1016/j.saa.2013.05.033 